\title{
Developing a Technology-supported Learning Model for Elementary Education Level
}

\section{Qiyun Wang}

National Institute of Education, Nanyang Technological University, Singapore

$\triangle$ qiyun.wang@nie.edu.sg

\begin{abstract}
Technology has been increasingly used to promote students' engagement in online learning environments. Engagement refers to the students' commitment or effort involved in learning. Engagement often has various categories such as behavioral, emotional, and cognitive engagement. In this paper, a technology-supported learning model is proposed for the purpose of promoting students' engagement in online learning. This model is composed of three key components: pedagogical design, social design, and technical design. Pedagogical design aims to achieve predefined learning objectives through well-designed instructional strategies and learning activities so that students can be behaviorally engaged (e.g., high participation, active exploration) and cognitively engaged (e.g., asking questions, giving evaluative comments). Social design is to create a comfortable and friendly setting where students are willing to interact with peers and/or with the teacher so that emotional engagement (e.g., positive social relationship between students and the teacher) and cognitive engagement (e.g., knowledge construction) can be attained. Technical design intends to create a usable platform that students can easily manipulate without technical difficulties. All these designs must take the context (e.g., elementary education level) into careful consideration.
\end{abstract}

Keywords: engagement, pedagogical design, social design, technical design.

How to Cite: Qiyun, W. (2019). Developing a Technology-Supported Learning Model for Elementary Education Level. Mimbar Sekolah Dasar, 6(1), 141-146. doi:http://dx.doi.org/10.17509/mimbar-sd.v6i1.15901.

INTRODUCTION Technology has become part of our modern life, and an increasing number of educational organizations opt to take online or blended learning mode (Chen, Lambert, \& Guidry, 2010). The number of students taking online or blended learning continues to increase. Enabling students to engage in online learning becomes crucial though some studies have shown that students are often more engaged in online or blended learning than in face-to-face learning (Henrie, Bodily, Manwaring, \& Graham, 2015). However, the higher level of engagement does not simply occur automatically, and deliberate instructional design is often needed. In this paper, a model for designing effective technologysupported learning environments is proposed to engage online students. This model, as shown in Figure 1, focuses on three designs (pedagogical, social, and technical) and three expected forms of engagement (behavioral, emotional, and cognitive). In the following sections, the designs and forms of engagement will be elaborated.

PEDAGOGICAL, SOCIAL, AND TECHNICAL DESIGNS 
Qiyun Wang, Developing a Technology-supported Learning Model...

The importance of the pedagogical design, social design, and technical design (PST) has been articulated in much published literature (e.g., Wang, 2008, 2009a), and the PST model has also been used to guide the design of many technology-supported learning environments (e.g., Wang, 2009b; Wang \& Huang, 2018). Compared to traditional instructional design models such as ADDIE model, the PST model enables teachers to design learning environments in a more flexible way (Wang, 2009a).

\section{Pedagogical Design}

The main purpose of pedagogical design to achieve learning objectives by carefully choosing proper instructional approaches, designing learning activities, and assessing students' learning outcomes. A major difference between a technologysupported learning environment and a purely entertaining environment such as a computer game is that the purpose of the learning environment is for learning, in particular for achieving certain learning objectives (Wang, 2009a). A few model can be used to guide the pedagogical design of a technology-supported learning environment. For instance, the curricular spider web model proposed by van den Akker (2013) includes ten essential components of a curriculum, which are: i) aims/objectives; ii) content; iii) learning activities; iv) teacher role; v) materials and resources; vi) grouping; vii) location; viii) time; ix) assessment; and $x$ ) rationale. He highlights that all the components are equally important and the lack of any component will lead to the failure of a curriculum. Undoubtedly, these components are also key elements of a technology-supported learning environment. In addition, The Gagne's nine events of classroom teaching also highlight key considerations for designing a lesson, such as motivating students to learn and informing students of learning objectives.

\section{Social Design}

Compared to learning using multimedia resources from CD-ROMs, which was a common learning form about 30 years ago, learning using network-enabled learning environments nowadays is quite different. Students do not simply learn from available online resources. But rather, they communicate and interact with their peers and the teacher using technological tools to co-construct knowledge (Scardamalia, 2002). The social design of a technologysupported learning environment is to provide a safe and friendly environment so that the students are willing to interact with others, from which they share their understanding, negotiate, and construct knowledge together (Wang, 2009a).

Some key considerations for the social design of a technology-supported learning environment include: setting up ground rules and norms for regulating their communication behavior; providing a range of communication channels such as text chat, audio, or video for easy communication; supporting various communication forms such as synchronous 
(e.g., real-time video conferencing) or asynchronous (e.g., discussion forum) sharing.

\section{Technical Design}

Compared to a traditional classroom setting, the implementation of a technology-supported learning environment more heavily depends of the support of technology, and technology plays a more crucial rule in a technologysupported learning environment. In terms of technical design, instructional designers must carefully consider the affordances of available technological tools and choose the most appropriate tool for students to complete learning activities (Wang, 2008). Interface design, ease of learning, ease of use, and minimal technical difficulty must be carefully considered. In addition, technical support is also critical for the successful implementation of a learning environment. Students will be frustrated if they cannot receive prompt support when they encounter technical problems.

\section{Context}

All the above design aspects must take the context into careful consideration. The pedagogical, social, and technical designs for primary school pupils are obviously different from for university adult students. Similarly, a technology-supported learning environment for a specific country like Indonesia is different from a MOOC designed for international students. Therefore, the context often affects or restricts the design and implementation of a technology-supported learning environment.

Instructional designers must consider the cultural context of the intended learners, available infrastructure (e.g., hardware, software), and the characteristics of learners. A well pedagogically, socially and technically designed learning environment may not be feasible in another culturally different context.
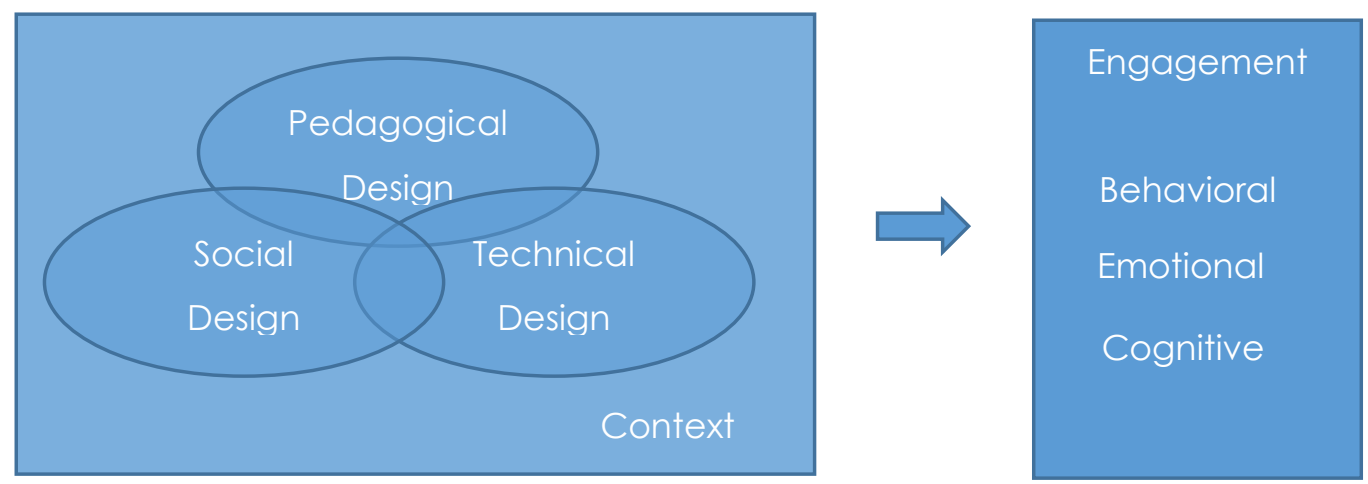

Figure 1. Technology-based Learning Model for Engagement.

BEHAVIORAL, EMOTIONAL, AND COGNITIVE ENGAGEMENT
The purpose of pedagogical, social, and technical designs of a technologysupported learning environment is to 
Qiyun Wang, Developing a Technology-supported Learning Model...

engage students so that they can learn actively and hence achieve learning objectives. Engagement often refers to the students' commitment or effort involved in the learning process (Fredricks, Blumenfeld, \& Paris, 2004). Though engagement is an internal mental process, it can be monitored based on some observable indicators. The indicators are often grouped into behavioral, motional, and cognitive categories.

\section{Behavioral Engagement}

Behavioral engagement includes the observable behaviors necessary to the achievement of learning objectives, such as attendance, participation, and assignment completion (Fredricks, Blumenfeld, \& Paris, 2004). In a technologysupported learning environment, behavioral engagement indicators often include the number/frequency of visits, the number of clicks, the duration of web views, the number of posts, the time-on-task (Kong, 2011 ), or, number of page views, time spent on pages (Henrie et al., 2015). Behavioral engagement is observable. Its indicators can be captured through classroom observation, or the big data stored in the learning management system.

However, the indicators of behavioral engagement cannot fully represent the engagement level of online students. For instance, some students may purposely have many clicks but without deep learning invloved, or post many messages but at a very shallow level. To a certain extent, the behavioral indicators can only give a general sense of the students' engagement but may not be accurate.

\section{Emotional Engagement}

Emotional engagement include "both the feelings learners have about their learning experience, such as interest, frustration, or boredom, and their social connection with others at school' (Henrie et al., 2015, p37). To a certain extent, emotional engagement can also be observed by outsiders. But compared to behavioral engagement, some emotional indicators (e.g., anxiety, happiness, frustration, bored, likeness) are often less observable or quantifiable.

Emotional engagement reflects the degree that students like the online learning environment, the instructor, or the overall learning experience. Nevertheless, having a high level of emotional engagement does not mean that the students really learn something or construct meaningful knowledge. They may like the learning environment of the instructor simply because the environment is fun or the instructor is humorous, but they may learn little in terms of learning content. Therefore, having a high level of emotional engagement is a necessary condition for effective learning, but is not a sufficient condition.

\section{Cognitive Engagement}

Cognitive engagement refers to the focused effort learners give to understand the content or in completing learning 
activities (Fredricks, Blumenfeld, \& Paris, 2004). It often includes self-regulation and metacognitive behaviors. It is an internal process happened in the mind, and hence less observable than behavioral or emotional engagement and can only be inferred from certain indicators. Some of cognitive engagement indicators include (Fredricks \& Mccolskey, 2012):

- $\quad$ Asking/answering questions

- Contributing/enhancing

ideas/verbalizing thinking

- Making evaluative comments

- Justifying an argument

- Providing additional information

- Completing instructor/peer's

utterances

- Doing extra work and going beyond the requirement

According to Chi and Wylie (2014), cognitive engagement has four modes: passive, active, constructive, and interactive engagement. The passive mode of engagement refers to students 'being oriented toward and receiving information from the instructional materials without overtly doing anything else related to learning' (p. 221). An example of passive engagement is that a student reads a novel silently without sharing with friends or talking to others. The active mode of engagement involves 'some form of overt motoric action or physical manipulation' (Chi \& Wylie, 2014, p. 221). An example of active engagement is that a student actively click on some links or browse websites in an online learning environment. The constructive mode of engagement means that students produce or generate additional artefacts beyond the information given. For instance, a student may draw a concept map to show his/her understanding of the topic. The interactive mode engagement includes students' communication with others, or co-construction of artefacts together with others. An example of interactive engagement is that students share information, negotiate ideas, and construct knowledge in an online discussion forum.

\section{CONCLUDING REMARKS}

An effective technology-supported learning environment must engage students so that they are willing to devote time and effort to the completion of learning activities to achieve learning objectives. How to design a technologysupported learning environment to keep students engaged is a striking question for instructional designers. This paper proposes a model for designing technology-support learning environments for engaging students. This model suggests that an effective learning environment can be designed from the pedagogical, social, and technical perspectives, and take the context into consideration. Such a learning environment will have the potential to behaviorally, emotionally, and cognitively engage students.

\section{REFERENCES}

Chen, P. S. D., Lambert, A. D., \& Guidry, K. R. (2010). Engaging online learners: The impact of web-based learning technology on college student 
Qiyun Wang, Developing a Technology-supported Learning Model...

engagement. Computers \& Education, 54, 1222-1232.

Chi, T.H., \& Wylie, R. (2014). The ICAP framework: Linking cognitive engagement to active learning outcomes. Educational Psychologist, 49 (4), 219-243.

Fredricks, J. A., Blumenfeld, P. C., Paris, A.H. (2004). School engagement: Potential of the concept, state of the evidence. Review of Educational Research, 74 (1), 59-109.

Fredricks, J. A., \& McColskey, W. (2012). The measurement of student engagement: A comparative analysis of various methods and student self-report instruments. In S. L. Christenson, A. L. Reschly, \& C. Wylie (Eds.), Handbook of research on student engagement (pp. 763-782). New York, NY: Springer Science.

Henrie, C. R., Bodily, R., Manworning, K. C., \& Graham, C. (2015). Exploring intensive longitudinal measures of student engagement in blended learning. International Review of Research in Open and Distributed Learning, 16 (3), 131-155.

Kong, S.C. (2011). An evaluation study of the use of a cognitive tool in a one-toone classroom for promoting classroom-based dialogic interaction. Computers \& Education, 57, 1851-1864.

Scardamalia, M. (2002). Collective cognitive responsibility for the advancement of knowledge. In B. Smith (Ed.), Liberal education in a knowledge society (pp. 67-98). Chicago: Open Court.

Van den Akker, J. (2013). Curricular development research as a specimen of educational design research. In $\mathrm{N}$. Nieveen and Tj. Plomp (eds.), Educational Design Research (pp. 5271). Netherlands: SLO.

Wang, Q.Y (2008). A generic model for guiding the integration of ICT into teaching and learning. Innovations in Education and Teaching International, $45(3), 411-419$.
Wang, Q.Y. (2009a). Guiding teachers in the process of ICT integration: Analysis of three conceptual models.Educational Technology, 49 (5), 23-27.

Wang, Q.Y. (2009b). Designing a webbased constructivist learning environment. Interactive Learning Environments, 17 (1), 1-12.

Wang, Q.Y. \& Huang, C.Q. (2018). Pedagogical, social and technical designs of a blended synchronous learning environment. British Journal of Educational Technology, 49 (3), 451-462. 